\title{
Modeling Electron Competition among Nitrogen Oxides Reduction and N2O Accumulation in Hydrogenotrophic Denitrification
}

Liu, Yiwen; Ngo, Huu Hao; Guo, Wenshan; Peng, Lai; Chen, Xueming; Wang, Dongbo; Pan, Yuting; Ni, Bing-Jie

\section{Published in:}

Biotechnology and Bioengineering

Link to article, DOI:

10.1002/bit.26512

Publication date:

2018

Document Version

Peer reviewed version

Link back to DTU Orbit

Citation $(A P A)$ :

Liu, Y., Ngo, H. H., Guo, W., Peng, L., Chen, X., Wang, D., Pan, Y., \& Ni, B-J. (2018). Modeling Electron Competition among Nitrogen Oxides Reduction and N O Accumulation in Hydrogenotrophic Denitrification. Biotechnology and Bioengineering, 115(4), 978-988 . https://doi.org/10.1002/bit.26512

\section{General rights}

Copyright and moral rights for the publications made accessible in the public portal are retained by the authors and/or other copyright owners and it is a condition of accessing publications that users recognise and abide by the legal requirements associated with these rights.

- Users may download and print one copy of any publication from the public portal for the purpose of private study or research.

- You may not further distribute the material or use it for any profit-making activity or commercial gain

- You may freely distribute the URL identifying the publication in the public portal 


\title{
Modeling Electron Competition among Nitrogen Oxides Reduction and $\mathrm{N}_{2} \mathrm{O}$ Accumulation in Hydrogenotrophic Denitrification ${ }^{\dagger}$
}

\author{
Yiwen Liu ${ }^{1,2}$, Huu Hao Ngo ${ }^{1, *}$, Wenshan Guo', Lai Peng ${ }^{3}$, Xueming Chen ${ }^{4}$, \\ Dongbo Wang ${ }^{5}$, Yuting Pan ${ }^{6}$, Bing-Jie Ni ${ }^{7, *}$ \\ ${ }^{1}$ Centre for Technology in Water and Wastewater, School of Civil and Environmental \\ Engineering, University of Technology Sydney, Sydney, NSW 2007, Australia \\ ${ }^{2}$ Water Chemistry and Water Technology, Engler-Bunte-Institut, Karlsruhe Institute of \\ Technology, Karlsruhe, Germany \\ ${ }^{3}$ Research group of Sustainable Energy, Air and Water Technology, Department of \\ Bioscience Engineering, University of Antwerp, Antwerp 2020, Belgium \\ ${ }^{4}$ Process and Systems Engineering Center (PROSYS), Department of Chemical and \\ Biochemical Engineering, Technical University of Denmark, Building 229, 2800 Kgs. \\ Lyngby, Denmark \\ ${ }^{5}$ College of Environmental Science and Engineering, Hunan University, Changsha \\ 410082, China; Key Laboratory of Environmental Biology and Pollution Control \\ (Hunan University), Ministry of Education, Changsha 410082, China \\ ${ }^{6}$ Department of Environmental Science and Engineering, School of Architecture and \\ Environment, Sichuan University, Chengdu, Sichuan 610065, China \\ ${ }^{7}$ State Key Laboratory of Pollution Control and Resources Reuse, College of \\ Environmental Science and Engineering, Tongji University, Shanghai 200092, China \\ *Corresponding authors: \\ Prof Dr. Bing-Jie Ni, Tel.: +86 21 65986849; Fax: +86 21 65983602; E-mail \\ bjni@tongji.edu.cn \\ Prof Dr. Huu Hao Ngo, Tel.: +61 29514 2745; Fax: +61 29514 2633; E-mail \\ ngohuuhao121@gmail.com
}

†This article has been accepted for publication and undergone full peer review but has not been through the copyediting, typesetting, pagination and proofreading process, which may lead to differences between this version and the Version of Record. Please cite this article as doi: [10.1002/bit.26512]

Additional Supporting Information may be found in the online version of this article.

This article is protected by copyright. All rights reserved

Received September 29, 2017; Revision Received November 20, 2017; Accepted December 4, 2017

This article is protected by copyright. All rights reserved 


\begin{abstract}
Hydrogenotrophic denitrification is a novel and sustainable process for nitrogen removal, which utilizes hydrogen as electron donor and carbon dioxide as carbon source. Recent studies have shown that nitrous oxide $\left(\mathrm{N}_{2} \mathrm{O}\right)$, a highly undesirable intermediate and potent greenhouse gas, can accumulate during this process. In this work, a new mathematical model is developed to describe nitrogen oxides dynamics, especially $\mathrm{N}_{2} \mathrm{O}$, during hydrogenotrophic denitrification for the first time. The model describes electron competition among the four steps of hydrogenotrophic denitrification through decoupling hydrogen oxidation and nitrogen reduction processes using electron carriers, in contrast to the existing models that couple these two processes and also do not consider $\mathrm{N}_{2} \mathrm{O}$ accumulation. The developed model satisfactorily describes experimental data on nitrogen oxides dynamics obtained from two independent hydrogenotrophic denitrifying cultures under various hydrogen and nitrogen oxides supplying conditions, suggesting the validity and applicability of the model. The results indicated that $\mathrm{N}_{2} \mathrm{O}$ accumulation would not be intensified under hydrogen limiting conditions, due to the higher electron competition capacity of $\mathrm{N}_{2} \mathrm{O}$ reduction in comparison to nitrate and nitrite reduction during hydrogenotrophic denitrification. The model is expected to enhance our understanding of the process during hydrogenotrophic denitrification and the ability to predict $\mathrm{N}_{2} \mathrm{O}$ accumulation. This article is protected by copyright. All rights reserved
\end{abstract}

Key words: Hydrogenotrophic denitrification; Nitrous oxide; Electron competition; Mathematical modeling

This article is protected by copyright. All rights reserved 


\section{Introduction}

Biological denitrification is recognized as one of the most efficient methods for nitrate-contaminated water treatment, which can be achieved through both heterotrophic (with organic carbon sources as electron donors) and autotrophic (with inorganic carbon sources as electron donors) processes (Peng et al., 2016, Rivett et al., 2008, Wang et al., 2017b). Among them, autohydrogenotrophic denitrification, using hydrogen as electron donors and inorganic carbon species as carbon source, is a novel and sustainable process to achieve effective nitrate removal. Its advantages over heterotrophic denitrification include the lower operational cost (hydrogen compared to methanol or acetate) and lower sludge production rate (Karanasios et al., 2010, Rivett et al., 2008). As such, extensive work has been conducted on the promising hydrogenotrophic denitrification process in both bench and pilot scales, focusing on the reaction kinetics, effects of the ratio among hydrogen, nitrate and carbon dioxide, microbial ecology, reactor configurations for better hydrogen delivery, and other relevant operating parameters (Ghafari et al., 2009b, Kurt et al., 1987, Lee and Rittmann, 2003, Li et al., 2013, Nerenberg, 2016, Nerenberg et al., 2008, Rezania et al., 2005, Sahu et al., 2009, Smith et al., 2005, Zhao et al., 2013a, Zhao et al., 2013b, Zhao et al., 2011).

The complete hydrogenotrophic denitrification is a four-step sequential reduction process from nitrate $\left(\mathrm{NO}_{3}{ }^{-}\right)$to nitrogen gas $\left(\mathrm{N}_{2}\right)$ via nitrite $\left(\mathrm{NO}_{2}{ }^{-}\right)$, nitric oxide (NO) and nitrous oxide $\left(\mathrm{N}_{2} \mathrm{O}\right)$, with four specific denitrifying enzymes, namely nitrate reductase (Nar), nitrite reductase (Nir), NO reductase (Nor) and $\mathrm{N}_{2} \mathrm{O}$ reductase (Nos), involved (Ghafari et al., 2009a, 2010). $\quad \mathrm{N}_{2} \mathrm{O}$, a highly undesirable significant intermediate, can thus accumulate and subsequently emit to the atmosphere during hydrogenotrophic denitrification, which has raised increasing concerns due to its 
potent greenhouse gas effect and ozone depleting ability (Liu et al., 2016, Liu et al., 2017, Ravishankara et al., 2009). It has been reported that the amount of $\mathrm{N}_{2} \mathrm{O}$ accumulation in hydrogenotrophic denitrification system ranged from $0.05 \%$ to $15.2 \%$ of the influent nitrogen load ( $\mathrm{Li}$ et al., 2017). Therefore, understanding $\mathrm{N}_{2} \mathrm{O}$ accumulation in hydrogenotrophic denitrification is of great importance.

The accumulation of denitrification intermediates is often considered to be related to the electron competition among nitrogen oxides reductases responsible for the fourstep denitrification (Liu et al., 2015, Pan et al., 2013a, Pan et al., 2013b). Increasing evidence has shown that these key enzymes acquire electrons from a common electron supply source in the electron transport chain (Pan et al., 2015, Richardson et al., 2009), and the shortage of electron supply (i.e., the supply rate does not meet the demand for electron consumption rate by the four reduction steps) would induce the occurrence of the electron competition during hydrogenotrophic denitrification. Therefore, factors that could lower the hydrogen oxidation rate would lead to the accumulation of intermediates (e.g., $\mathrm{N}_{2} \mathrm{O}$ ) during hydrogenotrophic denitrification, such as hydrogen/carbon dioxide supply rate (Li et al., 2017).

Mathematical models have been widely used to predict nitrate and nitrite dynamics during hydrogenotrophic denitrification (Martin et al., 2013, Tang et al., 2012a, b, Tang et al., 2011). In contrast, little effort has been dedicated to modeling the $\mathrm{N}_{2} \mathrm{O}$ dynamics during hydrogenotrophic denitrification despite of considerable amounts of $\mathrm{N}_{2} \mathrm{O}$ accumulation in this process and its detrimental impact on the atmosphere (Li et al., 2017). Current existing models have been proposed to describe hydrogenotrophic denitrification as one-step or two-step denitrification (Martin et al., 2013, Rezania et al., 2005, Vasiliadou et al., 2006), without consideration of $\mathrm{N}_{2} \mathrm{O}$ production. Further, these models that couple the catabolic and anabolic processes do 
not consider electron competition among different steps of hydrogenotrophic denitrification as well as the effect of carbon dioxide on denitrifier metabolism, and thus would not be able to predict $\mathrm{N}_{2} \mathrm{O}$ accumulation under hydrogen- or carbon dioxide-limiting conditions ( $\mathrm{Li}$ et al., 2017).

This study aims to develop a new hydrogenotrophic denitrification model for describing nitrogen oxides reduction and $\mathrm{N}_{2} \mathrm{O}$ accumulation that takes electron competition among four nitrogen oxides reduction steps into account, and can be used as a practical tool for predicting $\mathrm{N}_{2} \mathrm{O}$ accumulation during hydrogenotrophic denitrification. To this end, the complex biochemical reactions and electron transfer processes involved are lumped into two oxidation (catabolic and anabolic hydrogen oxidation) and four reduction reactions, by using the linkage of electron carriers. The validity and applicability of the developed model is tested with previous experimental data on nitrogen oxides and $\mathrm{N}_{2} \mathrm{O}$ dynamics from two hydrogenotrophic denitrifying cultures under different experimental conditions. The findings of this work are expected to provide first insight into understanding of intermediate accumulation (e.g. $\mathrm{N}_{2} \mathrm{O}$ ) during hydrogenotrophic denitrification.

\section{Materials and methods}

\section{Model development}

In this work, we proposed the first model satisfactorily describing nitrogen dynamics and $\mathrm{N}_{2} \mathrm{O}$ accumulation in hydrogenotrophic denitrification through employing an effective modeling approach previously reported for describing electron competition in such biological processes (Ni et al., 2014, Pan et al., 2013b). The model proposed in this work decouples and links the hydrogen oxidation (e.g., catabolic and anabolic) with nitrogen oxides compound reduction processes (from $\mathrm{NO}_{3}{ }^{-}$to $\mathrm{N}_{2}$ via $\mathrm{NO}_{2}{ }^{-}$, NO and $\mathrm{N}_{2} \mathrm{O}$ ) through the introduction of electron carriers 
during the electron transfer processes (Pan et al., 2013b), to describe all potential intermediate (e.g., $\mathrm{N}_{2} \mathrm{O}$ ) accumulation steps during hydrogenotrophic denitrification. In particular, Mred and Mox are defined as the respective reduced and oxidized states of electron carriers in the model. Considering the relatively small size of electron carrier pool (Gyan et al., 2006), the continued availability of Mred and Mox depends on their concomitant regeneration, which is modeled by a recirculation loop between Mred and Mox $\left(\right.$ Mred $\left.\rightleftharpoons \operatorname{Mox}+2 \mathrm{e}^{-}+2 \mathrm{H}^{+}\right)$, i.e., a decrease in Mred being offset by an increase in Mox and vice versa, with the total amount of electron carriers $\left(C_{t o t}\right)$ keeping constant $\left(S_{\text {Mred }}+S_{\text {Mox }}=C_{t o t}\right)$. This approach has also been widely applied for other biological systems with electron competition (Fisher et al., 2015). Further, the model parameters have become more unified, especially electron affinity constant during denitrification (Pan et al., 2015, Sabba et al., 2017).

Specifically, the oxidation of hydrogen during hydrogenotrophic denitrification is modeled by the respective catabolic (Reaction 1) and anabolic (Reaction 2) hydrogen oxidation processes, where Mox is reduced to Mred by receiving electrons generated from hydrogen oxidation:

Reaction 1: catabolic hydrogen oxidation

$\mathrm{H}_{2}+\mathrm{Mox} \rightarrow$ Mred

Reaction 2: anabolic hydrogen oxidation

$$
3 \mathrm{H}_{2}+\mathrm{CO}_{2}+\frac{1}{5} \mathrm{NH}_{3}+M o x \rightarrow \frac{1}{5} \mathrm{C}_{5} \mathrm{H}_{7} \mathrm{O}_{2} \mathrm{~N}+\text { Mred }+\frac{8}{5} \mathrm{H}_{2} \mathrm{O}
$$

Nitrogen oxides reduction during hydrogenotrophic denitrification is modelled as four-step processes (Reactions 3 to 6), where Mred is oxidized to Mox by donating two electrons to a nitrogen oxide:

Reaction 3: Nitrate reduction to nitrite

$\mathrm{NO}_{3}{ }^{-}+$Mred $\rightarrow \mathrm{NO}_{2}{ }^{-}+\mathrm{Mox}+\mathrm{H}_{2} \mathrm{O}$ 
Reaction 4: Nitrite reduction to nitric oxide

$\mathrm{NO}_{2}{ }^{-}+\frac{1}{2}$ Mred $+\mathrm{H}^{+} \rightarrow \mathrm{NO}+\frac{1}{2} \mathrm{Mox}+\mathrm{H}_{2} \mathrm{O}$

Reaction 5: Nitric oxide reduction to nitrous oxide

$\mathrm{NO}+\frac{1}{2}$ Mred $\rightarrow \frac{1}{2} \mathrm{~N}_{2} \mathrm{O}+\frac{1}{2} \mathrm{Mox}+\frac{1}{2} \mathrm{H}_{2} \mathrm{O}$

Reaction 6: Nitrous oxide reduction to nitrogen gas

$\mathrm{N}_{2} \mathrm{O}+$ Mred $\rightarrow \mathrm{N}_{2}+\mathrm{Mox}+\mathrm{H}_{2} \mathrm{O}$

The stoichiometry and kinetics of the above reaction equations are summarized in Table 1. The Michaelis-Menten equation is used to describe kinetics of these enzymatic reaction rates. Each reaction rate is described as a function of the concentration of substrates involved. Table S1 in the Supporting Information (SI) lists the definitions, values, units, and sources of all parameters used in the developed model. It should be noted that regeneration of Mred and Mox in the model represents a modeling concept and method, which may not reflect the complex biochemical reactions in reality (Ni et al., 2014, Pan et al., 2013b).

\section{Experimental data used for model evaluation}

Experimental data from $\mathrm{Li}$ et al. (2017) on $\mathrm{N}_{2} \mathrm{O}$ emission during hydrogenotrophic denitrification were used to calibrate and validate the model. Li et al. (2017) used a hydrogen gas- and nitrate-fed denitrifying culture, acclimated and cultivated for 54 months continuously in three parallel 2-L lab-scale continuous-flow reactors at $\mathrm{pH} 7.0 \pm 0.5$ at $30 \pm 1{ }^{\circ} \mathrm{C}$, with a cycle time of $12 \mathrm{~h}$, to study the $\mathrm{N}_{2} \mathrm{O}$ accumulation during hydrogenotrophic denitrification. Several sets of batch tests were conducted in a $600-\mathrm{mL}$ sealed reactor (a headspace of $450 \mathrm{~mL}$ ) with the synthetic feed water and culture from the parent reactors: (1) effects of electron acceptors: nitrate or $\mathrm{N}_{2} \mathrm{O}$ was supplied at the beginning as the sole electron acceptor, at a mass inorganic carbon to nitrogen $(\mathrm{IC} / \mathrm{N})$ ratio of 1.8 , a temperature of $30{ }^{\circ} \mathrm{C}$ and a constant 
dissolved hydrogen concentration of $0.40 \mathrm{mg} / \mathrm{L}$; (2) effects of initial IC/N ratios: three batch tests were carried out with the initial mass IC/ $\mathrm{N}$ ratio of $0,0.18$ and 1.8 , using nitrate as the sole electron acceptor at a temperature of $30{ }^{\circ} \mathrm{C}$ and a constant dissolved hydrogen concentration of $0.40 \mathrm{mg} / \mathrm{L}$; (3) effects of dissolved hydrogen concentrations: three batch experiments were performed at a constant dissolved hydrogen concentration of $0.02,0.17$ and $0.40 \mathrm{mg} / \mathrm{L}$, with nitrate as the sole electron acceptor at a temperature of $30{ }^{\circ} \mathrm{C}$ and an initial mass IC/N ratio of 1.8; and (4) effects of temperatures: four batch tests were conducted at a temperature of 20, 25, 30 and 35 ${ }^{\circ} \mathrm{C}$, with nitrate as the sole electron acceptor at an initial mass IC/ $\mathrm{N}$ ratio of 1.8 and a constant dissolved hydrogen concentration of $0.40 \mathrm{mg} / \mathrm{L}$. At the beginning of a batch test, $140 \mathrm{~mL}$ of the synthetic feedwater was added to each batch reactor, and then 10 $\mathrm{mL}$ of the centrifugal stock culture taken from the parent reactors was inoculated. During the test, the initial nitrate or nitrite concentration was controlled at approximately 40 mg-N/L using $\mathrm{KNO}_{3}$ or $\mathrm{KNO}_{2}$. Pure $\mathrm{N}_{2} \mathrm{O}$ gas (99.99\%) was supplied to the batch reactor to control an initial $\mathrm{N}_{2} \mathrm{O}$ concentration of $60 \mathrm{mg}-\mathrm{N} / \mathrm{L}$ for the batch test with $\mathrm{N}_{2} \mathrm{O}$ as the sole electron acceptor. $\mathrm{NaHCO}_{3}$ was used as the inorganic carbon source. The $\mathrm{pH}$ was controlled at 7.0 during the tests by adding 0.2 $\mathrm{M} \mathrm{HCl}$ and $0.2 \mathrm{M} \mathrm{NaOH}$ solutions. The temperature was adjusted with a temperature adjustable incubator. The hydrogen gas produced by in-situ electrolysis and pure argon gas supplied were used to control that the volume percentage of the hydrogen in the headspace and thus ensure the dissolved hydrogen concentration in the liquid phase through gas-liquid transfer. Samples were taken periodically for $\mathrm{NO}_{3}{ }^{-}, \mathrm{NO}_{2}{ }^{-}$ and $\mathrm{N}_{2} \mathrm{O}$ analysis. More details of the reactor operation and batch test can be found in Li et al. (2017). 
Experimental data from Ghafari et al. (2009a and 2009b) by using a hydrogenotrophic denitrifying culture developed in bench-scale sequencing batch reactors were applied to further evaluate the model. Acclimatization was accomplished throughout multiple cycles with sequencing stages of settle, decant, fill, and react where complete nitrate and nitrite depletion was achieved. Each cycle lasted for $24 \mathrm{~h}$ while the reaction stage lasted for $23 \mathrm{~h}$. Two types of batch experiments were carried out in a 2.5 or 4 -L sealed reactor with the synthetic feed water and culture at the ambient temperature $\left(25 \pm 5^{\circ} \mathrm{C}\right)$ : (1) effects of nitrate concentrations (20, 30 and 50 mg-N/L) at an initial IC concentration of $2.5 \mathrm{~g} / \mathrm{L} \mathrm{NaHCO}_{3}$ and (2) effects of IC concentrations $\left(0,20,200\right.$ and $1250 \mathrm{mg} / \mathrm{L}$ as $\left.\mathrm{NaHCO}_{3}\right)$ at an initial nitrate of $20 \mathrm{mg}$ $\mathrm{N} / \mathrm{L} \cdot \mathrm{NaNO}_{3}$ and $\mathrm{NaHCO}_{3}$ were used as nitrate and inorganic carbon source, respectively. The initial dissolved hydrogen concentration was controlled at a saturated level by sparging hydrogen gas to the liquid phase of the reactor. Samples were taken periodically for $\mathrm{NO}_{3}{ }^{-}$and $\mathrm{NO}_{2}{ }^{-}$analysis. More details of the reactor operation and batch test can be found in Ghafari et al. (2009a and 2009b).

\section{Testing the predictive power of the model}

The developed model includes 17 stoichiometric and kinetic parameters as summarized in Table S1 in SI. About 13 of these model parameter values are well established in previous studies (SI). Thus, literature values were directly adopted for these parameters (SI Table S1) to simplify the model calibration procedure. In this work, the hydrogenotrophic denitrifiers were acclimated, cultivated and studied in hydrogen-unlimiting conditions. Therefore, the concentration range applied would not affect half-saturation constant during simulation. The remaining four parameters, i.e., maximum hydrogen oxidation rate ( $\left.\mathrm{r}_{\mathrm{h} 2, \max }\right)$, maximum nitrate reduction rate $\left(\mathrm{r}_{\mathrm{NO}, \max }\right)$, maximum nitrite reduction rate $\left(\mathrm{r}_{\mathrm{NO} 2, \max }\right)$ and maximum $\mathrm{N}_{2} \mathrm{O}$ reduction rate $\left(\mathrm{r}_{\mathrm{N} 2 \mathrm{O}, \max }\right)$, 
which are the key parameters governing the electron competition during hydrogenotrophic denitrification, are then calibrated using experimental data (SI Table S1). As the batch experiments were operated during short periods in batch mode, both biomass and decay were insignificant. The initial biomass concentrations were set based on convergence simulation of the continuous-flow of the parent reactor. $\mathrm{C}_{\text {tot }}$ (the sum of $S_{\text {Mox }}$ and $S_{\text {Mred }}$ ) was set with a value of $0.01 \mathrm{mmol} / \mathrm{g}-\mathrm{VSS}$ and $S_{\text {Mox }}=S_{\text {Mred }}$ at the initial stage based on previously reported literature (Pan et al. 2013). This is acceptable as the absolute value of $\mathrm{C}_{\text {tot }}$ is not critical for model simulation calibration and prediction.

Parameter values were estimated by minimizing the sum of squares of the deviations between the measured data and the model predictions using the secant method embedded in AQUASIM 2.1d (Reichert, 1998). Experimental data $\left(\mathrm{NO}_{3}{ }^{-}\right.$, $\mathrm{NO}_{2}{ }^{-}$and $\mathrm{N}_{2} \mathrm{O}$ ) from the batch test (1) - (3) of Li et al. (2017) were used to calibrate the model. Model validation was then carried out with the calibrated model parameters using the batch test (4) from Li et al. (2017) under different temperatures. The effect of temperate on a reaction rate was described by a modified Arrhenius equation according to Hao et al. (2002). To further verify the validity and applicability of the developed model, we also applied the model to evaluate two batch experimental data sets $\left(\mathrm{NO}_{3}{ }^{-}\right.$and $\mathrm{NO}_{2}{ }^{-}$) from Ghafari et al. (2009a and 2009b) using a different hydrogenotrophic denitrifying culture.

With the validated model, the model simulations were then conducted to provide insight into the electron competition between nitrogen oxides reductions under different conditions. The calculation of the electron consumption rates by each step of denitrification was according to Pan et al. (2013a). Specifically, the impact of electron acceptor combination (i.e., simultaneous addition of two or three among $\mathrm{NO}_{3}{ }^{-}, \mathrm{NO}_{2}^{-}$, 
and $\mathrm{N}_{2} \mathrm{O}$ ) on nitrogen oxides reduction and the impact of hydrogen concentration levels on electron distribution pattern with two or three nitrogen oxides added were analysed using the model.

\section{Results}

\section{Model Calibration}

The calibration of the new model was performed based on the optimization of the key model parameters values governing the electron competition during hydrogenotrophic denitrification (i.e., $\mathrm{r}_{\mathrm{h} 2, \max }, \mathrm{r}_{\mathrm{NO} 3 \text {, max }}, \mathrm{r}_{\mathrm{NO} 2 \text {, max }}$ and $\mathrm{r}_{\mathrm{N} 2 \mathrm{O}, \max }$ ), by fitting the model predicted data to the results of batch test (1) - (3) from Li et al. (2017). The experimental data and model prediction of $\mathrm{NO}_{3}{ }^{-}, \mathrm{NO}_{2}{ }^{-}$and $\mathrm{N}_{2} \mathrm{O}$ are presented in Figure 1 . The calibrated parameter values giving the optimum model fittings with the experimental data are listed in Table S1. The concentrations of initial electron acceptor (batch test $1, \mathrm{NO}_{3}{ }^{-}$or $\mathrm{N}_{2} \mathrm{O}$ ) both display linear decrease. The $\mathrm{N}_{2} \mathrm{O}$ reduction rate (i.e., $1.44 \mathrm{mmol} / \mathrm{L} / \mathrm{h}$ ) with $\mathrm{N}_{2} \mathrm{O}$ as the sole initial electron acceptor (Figure $1 \mathrm{~b}$ ) was much higher than that of with nitrate (i.e., $0.51 \mathrm{mmol} / \mathrm{L} / \mathrm{h}$, Figure $1 \mathrm{a}$ ). With the decrease of IC/N ratios from 1.8 to 0.18 and 0 (batch test 2, Figures $1 \mathrm{a}, 1 \mathrm{c}$ and $1 \mathrm{~d}$ ), the nitrate reduction rate decreased from 0.56 to 0.44 and $0.31 \mathrm{mmol} / \mathrm{L} / \mathrm{h}$, along with less nitrite accumulation. The $\mathrm{N}_{2} \mathrm{O}$ concentrations were all quite low and the reduction rates were similar, indicating the insignificant impact of the IC/N ratio on $\mathrm{N}_{2} \mathrm{O}$ accumulation during hydrogenotrophic denitrification. Similarly, the nitrate reduction rates decreased from 0.56 to 0.40 and $0.20 \mathrm{mmol} / \mathrm{L} / \mathrm{h}$ while nitrite accumulation decreased, with the decrease of hydrogen concentrations from 0.40 to 0.17 and 0.02 mg/L (batch test 3, Figures $1 \mathrm{a}, 1 \mathrm{e}$ and $1 \mathrm{f}$ ). The $\mathrm{N}_{2} \mathrm{O}$ accumulation levels were also very low and similar, likely due to the continuous hydrogen supply even though the initial concentration of hydrogen decreased. The model predictions captured these 
trends reasonably well. The agreement between the simulated and measured data supported that the developed model properly captures the relationships among nitrogen oxides reduction. Sensitivity analyses were conducted to evaluate the model structure and to investigate the most determinant biokinetic parameters on the system performance in terms of $\mathrm{NO}_{3}{ }^{-}, \mathrm{NO}_{2}^{-}$and $\mathrm{N}_{2} \mathrm{O}$ accumulation using the AQUASIM built-in algorithms, with results shown in Figures S1 in SI. Specifically, the nitrate and nitrite variation of the system is most sensitive to maximum nitrite reduction rate $\left(\mu_{\mathrm{NO} 2}\right)$, maximum hydrogen oxidation rate $\left(\mu_{\mathrm{H} 2}\right)$ and maximum nitrate reduction rate ( $\mu_{\mathrm{NO} O 3}$ ) under studied conditions. In contrast, the $\mathrm{N}_{2} \mathrm{O}$ variation is insensitive to biokinetic parameters under studied conditions.

\section{Model validation}

The developed model and calibrated parameter set (Table S1) were then further tested for their ability to predict nitrate, nitrite and $\mathrm{N}_{2} \mathrm{O}$ dynamics in batch test 4 of $\mathrm{Li}$ et al. (2017) under different temperature conditions (i.e., 20, 25 and $35{ }^{\circ} \mathrm{C}$ ). The model predictions and the experimental results are shown in Figure 2. As the temperature increased from 20 to $35{ }^{\circ} \mathrm{C}$, nitrate was consumed faster along with less nitrite and $\mathrm{N}_{2} \mathrm{O}$ accumulation (Figures $1 \mathrm{a}$ and 2), coincident with the dependency of biological reaction rates on moderate temperatures. The validation results showed that the model predictions well matched the measured data of nitrogen oxides reduction in the validation experiment, which supports the validity of the developed model.

\section{Model evaluation using a different hydrogenotrophic denitrifying culture}

The experimental results obtained from Ghafari et al. (2009a and 2009b) with a different hydrogenotrophic denitrifying culture were used to evaluate the developed model in terms of $\mathrm{NO}_{3}{ }^{-}$and $\mathrm{NO}_{2}{ }^{-}$dynamics. As expected in Figure 3 under the same initial $\mathrm{NaHCO}_{3}$ concentration, longer nitrate consumption period and higher nitrite 
accumulation was observed with the increase of initial nitrate concentrations from 20 to $50 \mathrm{mg}-\mathrm{N} / \mathrm{L}$. In Figure 4, the increase of the initial $\mathrm{NaHCO}_{3}$ dose from 0 to 1250 $\mathrm{mg} / \mathrm{L}$ at an initial nitrate concentration of $20 \mathrm{mg}-\mathrm{N} / \mathrm{L}$ resulted in better denitrification rates due to the enhanced anabolic hydrogen oxidation. Nitrite accumulation was observed before complete nitrate reduction. Also, hydrogentrophic denitrification could be accomplished in the absence of IC (Figure 4a). The model captured these trends reasonably well, further suggesting the applicability of the developed model.

\section{Impact of electron acceptor combination on nitrogen oxides reduction}

Electron competition in the presence of multiple nitrogen oxides combinations (i.e., simultaneous addition of two or three among $\mathrm{NO}_{3}{ }^{-}, \mathrm{NO}_{2}{ }^{-}$, and $\mathrm{N}_{2} \mathrm{O}$ ) may lead to decreased reduction rates of all nitrogen oxides compounds involved in comparison to the rate measured with a single nitrogen oxides present during denitrification (Pan et al., 2013b). Such profound impact of electron competition during hydrogenotrophic denitrification was analyzed with the model of this work (Figure 5a). As a validation, the simulated nitrogen oxides reduction rates closely match to the experimentally determined rates with a single nitrogen oxide present when hydrogen and IC are in excess. The nitrogen oxides reduction rates in the presence of multiple nitrogen oxides compounds were then predicted. It can be found that the highest nitrate, nitrite, or $\mathrm{N}_{2} \mathrm{O}$ reduction rates could be always achieved in the presence of the single respective nitrogen oxide as the electron acceptor during hydrogenotrophic denitrification.

The electron consumption rates of each reductase under different scenarios of electron addition schemes (i.e., different nitrogen oxides combinations) were also simulated (Figure 5b). Similarly, the highest respective rates during hydrogenotrophic denitrification were attained with the addition of single nitrogen oxide. Also, the total 
electron consumption rates (i.e., sum of the rates of four hydrogenotrophic denitrification reductases) were almost constant in the presence of multiple nitrogen oxides. Most electrons distributed to $\mathrm{N}_{2} \mathrm{O}$ reductase once it was added as one of the electron donors, due to the higher maximum reduction rate of $\mathrm{N}_{2} \mathrm{O}$ in comparison to $\mathrm{NO}_{3}{ }^{-}$and $\mathrm{NO}_{2}{ }^{-}$under non-hydrogen-and-IC-limiting conditions.

\section{Impact of hydrogen concentrations on electron distribution pattern with two or} three nitrogen oxides added

Six hydrogen addition schemes (i.e., C, H1, H2, H3, H4, and H5) were simulated to mimic the effect of the intensity of electron competition under hydrogen limiting conditions on electron distribution pattern in the presence of multiple nitrogen oxides (Figure 6). Hydrogen addition schemes C stands for hydrogen pulse feeding (12 mmol/L), and H1, H2, H3, H4, and H5 stand for hydrogen slow feeding with loading rates of $12,6,2.4,1.2,0.6 \mathrm{mmol} /(\mathrm{L} \times \mathrm{h}))$, respectively. The decrease of hydrogen supply (from $\mathrm{C}$ to $\mathrm{H} 5$ ) resulted in the decreased electron consumption rates (Figures $6 b, d, f$ and $h)$. Also, it enhanced the intensity of electron competition. More electrons distributed to $\mathrm{NO}_{2}{ }^{-}$reductase under hydrogen limiting conditions when $\mathrm{NO}_{2}{ }^{-}$was added (Figures 6a, e and g) due to the lower $S_{\text {Mred }}$ affinity constant for Nir $\left(\mathrm{K}_{\mathrm{Mred}, 2}\right)$. However, it was not evident when $\mathrm{N}_{2} \mathrm{O}$ was added (Figures 6 e and g), due to the higher maximum $\mathrm{N}_{2} \mathrm{O}$ reduction rate. Therefore, the electron distribution to $\mathrm{N}_{2} \mathrm{O}$ was almost constant (Figures 6c, e and g) with two or three nitrogen oxides added under hydrogen limiting conditions.

\section{Discussion}

Hydrogenotrophic denitrification is a promising and sustainable autotrophic nitrogen removal process. Recent studies have shown that $\mathrm{N}_{2} \mathrm{O}$ can accumulate during this process, which is a highly undesirable intermediate and potent greenhouse gas. It 
should be noted that $1 \%$ increase in $\mathrm{N}_{2} \mathrm{O}$ emission would induce $30 \%$ increase in carbon footprint during the wastewater treatment (Law et al., 2012). Therefore, modeling of $\mathrm{N}_{2} \mathrm{O}$ dynamics is of great importance for understanding $\mathrm{N}_{2} \mathrm{O}$ emission from hydrogenotrophic denitrification (Nerenberg, 2014, Ni et al., 2011, Ni et al., 2013, Wang et al., 2017a), which can serve as a powerful tool for guiding potential $\mathrm{N}_{2} \mathrm{O}$ mitigation strategies. However, modeling studies in denitrification to date have mainly focused on the $\mathrm{N}_{2} \mathrm{O}$ emission during heterotrophic denitrification in both wastewater (Ni et al., 2011, Pan et al., 2013) and soil systems (Ludwig et al., 2011, Zhang et al., 2011), with organic carbon sources as electron donors. The previously proposed hydrogenotrophic denitrification models completely overlook $\mathrm{N}_{2} \mathrm{O}$ production. Further, these models do not include a specific structure to describe the hydrogen oxidation process, thus are not able to predict the electron competition process among different steps of hydrogenotrophic denitrification and not applicable to predict $\mathrm{N}_{2} \mathrm{O}$ accumulation when the hydrogen oxidation rate limits the overall hydrogenotrophic denitrification rate.

In this work, a new mathematical model decoupling the catabolic and anabolic hydrogen oxidation with four-step nitrogen oxides reduction processes through the introduction of electron carriers is developed to describe all potential intermediate (e.g., $\mathrm{N}_{2} \mathrm{O}$ ) accumulation steps during hydrogenotrophic denitrification. Our model is the first model for describing the $\mathrm{N}_{2} \mathrm{O}$ dynamics and electron competition in the hydrogenotrophic denitrification system. In contrast to the previous model structure, the hydrogen oxidation process (Reactions 1 and 2) and the nitrogen reduction processes (Reactions 3 to 6) are modeled separately in our current model (Table 1), enabling the prediction of both the electron supply rate (i.e., hydrogen oxidation) and electron consumption rate (i.e., nitrogen reduction) particularly under a limited 
electron supplying flux. The relative electron competition ability of each denitrification step is modeled with different affinity constants for reduced carriers, which are key parameters to determine the electron distribution (Pan et al., 2013b). The validity of the developed model was confirmed by two independent hydrogenotrophic denitrification studies. The set of best-fit parameter values are shown in Table S1. The parameter values obtained were robust in their ability to predict nitrate, nitrite and $\mathrm{N}_{2} \mathrm{O}$ dynamics under different operational conditions, indicating the potential applicability of the developed model for different hydrogenotrophic denitrification systems. A systematic experimental evaluation on the processes in this system would take extremely a long time because of the slow growth rate of autotrophic bacteria. Under such circumstances, a modeling study by employing the current available published data to describe various key biological processes in this autotrophic system would be acceptable as well as valuable. The model of this work might be useful for better understanding, accurate estimation and possible mitigation of $\mathrm{N}_{2} \mathrm{O}$ emission from hydrogenotrophic denitrification systems.

It has been reported that nitrite reduction was prioritized over the other heterotrophic denitrification steps when electron supply (i.e., carbon) became the limiting step (Pan et al., 2013b). Also, the fractions of electrons distributed to $\mathrm{N}_{2} \mathrm{O}$ reductase decreased with the decrease of carbon loading rate, thus resulting in $\mathrm{N}_{2} \mathrm{O}$ accumulation. The reason could be attributed to a higher capacity of nitrite reduction for electron competition under electron limiting conditions (i.e., a low $S_{\text {Mred }}$ concentration), i.e., $\mathrm{K}_{\mathrm{Mred}, 2}$ ( $S_{\text {Mred }}$ affinity constant for $\mathrm{Nir}$ ) has a value that is approximately ten times lower than $\mathrm{K}_{\text {Mred,1 }}\left(S_{\text {Mred }}\right.$ affinity constant for Nar) and $\mathrm{K}_{\text {Mred,4 }}$ ( $S_{\text {Mred }}$ affinity constant for Nos). In contrast, with the same values of affinity constants for reduced carriers, the electron distribution to $\mathrm{N}_{2} \mathrm{O}$ was almost constant even with 
the substantial decrease of electron supply (i.e., hydrogen) during hydrogenotrophic denitrification in this work (Figure 6). This is likely due to the substantially higher $\mathrm{r}_{\mathrm{N} 2 \mathrm{O}, \max }$ (maximum $\mathrm{N}_{2} \mathrm{O}$ reduction rate) in comparison to $\mathrm{r}_{\mathrm{NO}, \max }$ (maximum nitrate reduction rate) and $\mathrm{r}_{\mathrm{NO} 2 \text {,max }}$ (maximum nitrite reduction rate) (Table 1). In fact, $\mathrm{N}_{2} \mathrm{O}$ accumulation depends on both maximum rate and substrate affinity constant. Parameters $\mathrm{r}_{\mathrm{N} 2 \mathrm{O} \text {,max }}$ and $\mathrm{K}_{\mathrm{N} 2 \mathrm{O}} / \mathrm{K}_{\mathrm{Mred}, 4}$ are highly correlated parameters. Higher $\mathrm{r}_{\mathrm{N} 2 \mathrm{O} \text {,max }}$ would offset the higher $\mathrm{K}_{\mathrm{N} 2 \mathrm{O}} / \mathrm{K}_{\mathrm{Mred}, 4}$, thus resulting a higher electron competition capacity of $\mathrm{N}_{2} \mathrm{O}$ reduction during hydrogenotrophic denitrification, as confirmed by the model simulation (Figure 6). Therefore, higher $\mathrm{N}_{2} \mathrm{O}$ accumulation would not occur even under hydrogen limiting conditions. Due to insufficient information of the electron competition process during hydrogenotrophic denitrification, the reaction kinetics were not well established. For instance, the maximum hydrogen oxidation rate $\left(\mathrm{r}_{\mathrm{H} 2 \text {,max }}\right)$, the key parameter to regulate the overall electron supply rate, is not available in literature. Also, the four electron affinity constants for different nitrogen reduction enzymes are adapted from the literature (Pan et al., 2013b) without calibration. Therefore, more efforts are required to collect more information on these key parameters for further model implementation.

\section{Conclusion}

In summary, a mathematical model is developed to describe $\mathrm{N}_{2} \mathrm{O}$ production during hydrogenotrophic denitrification for the first time. The complex biochemical reactions and electron transfer processes involved are lumped into two oxidation and four reduction reactions that are linked through electron carriers. The developed model has successfully reproduced the experimental data obtained from two independent hydrogenotrophic denitrifying cultures. Further model simulation results indicated that $\mathrm{N}_{2} \mathrm{O}$ accumulation would not be intensified even with the decrease of 
electron supply rate, due to the higher electron competition capacity of $\mathrm{N}_{2} \mathrm{O}$ reduction.

\section{Acknowledgement}

This work was partially supported by the Recruitment Program of Global Experts and the Natural Science Foundation of China (No. 51578391). Dr. Yiwen Liu acknowledges the support from the UTS Chancellor's Postdoctoral Research Fellowship and the support of Alexander von Humboldt-Foundation. The authors are grateful to the research collaboration.

\section{Conflict of Interest Disclosure}

The authors declare no conflict of interest. 


\section{References}

Fischer, K., Batstone, D., van Loosdrecht, M.C. and Picioreanu, C., 2015. A mathematical model for electrochemically active filamentous sulfide oxidising bacteria. Bioelectrochemistry 102, 10-20.

Ghafari, S., Hasan, M. and Aroua, M.K., 2009a. Effect of carbon dioxide and bicarbonate as inorganic carbon sources on growth and adaptation of autohydrogenotrophic denitrifying bacteria. J. Hazard. Mater. 162(2), 15071513.

Ghafari, S., Hasan, M. and Aroua, M.K., 2009b. Improvement of autohydrogenotrophic nitrite reduction rate through optimization of $\mathrm{pH}$ and sodium bicarbonate dose in batch experiments. J. Biosci. Bioeng. 107(3), 275280.

Ghafari, S., Hasan, M. and Aroua, M.K., 2010. A kinetic study of autohydrogenotrophic denitrification at the optimum $\mathrm{pH}$ and sodium bicarbonate dose. Bioresour. Technol. 101(7), 2236-2242.

Gyan, S., Shiohira, Y., Sato, I., Takeuchi, M. and Sato, T., 2006. Regulatory loop between redox sensing of the NADH/NAD+ ratio by Rex (YdiH) and oxidation of NADH by NADH dehydrogenase Ndh in Bacillus subtilis. J. Bacteriol. 188(20), 7062-7071.

Hao, X., Heijnen, J.J. and Van Loosdrecht, M.C., 2002. Model-based evaluation of temperature and inflow variations on a partial nitrification-ANAMMOX biofilm process. Water Res. 36(19), 4839-4849.

Karanasios, K., Vasiliadou, I., Pavlou, S. and Vayenas, D., 2010. Hydrogenotrophic denitrification of potable water: a review. J. Hazard. Mater. 180(1), 20-37.

Kurt, M., Dunn, I. and Bourne, J., 1987. Biological denitrification of drinking water using autotrophic organisms with $\mathrm{H} 2$ in a fluidized-bed biofilm reactor. Biotechnol. Bioeng. 29(4), 493-501.

Law, Y., Ye, L., Pan, Y. and Yuan, Z., 2012. Nitrous oxide emissions from wastewater treatment processes. Philosophical Transactions of the Royal Society B: Biological Sciences. 367(1593), 1265-1277.

Lee, K.-C. and Rittmann, B.E., 2003. Effects of $\mathrm{pH}$ and precipitation on autohydrogenotrophic denitrification using the hollow-fiber membrane-biofilm reactor. Water Res. 37(7), 1551-1556.

Li, P., Wang, Y., Zuo, J., Wang, R., Zhao, J. and Du, Y., 2017. Nitrogen removal and N2O accumulation during hydrogenotrophic denitrification: influence of environmental factors and microbial community characteristics. Environ. Sci. Technol. 57(2), 870-879.

Li, P., Xing, W., Zuo, J., Tang, L., Wang, Y. and Lin, J., 2013. Hydrogenotrophic denitrification for tertiary nitrogen removal from municipal wastewater using membrane diffusion packed-bed bioreactor. Bioresour. Technol. 144, 452-459.

Liu, Y., Peng, L., Chen, X. and Ni, B.-J., 2015. Mathematical Modeling of Nitrous Oxide Production during Denitrifying Phosphorus Removal Process. Environ. Sci. Technol. 49(14), 8595-8601. 
Liu, Y., Peng, L., Ngo, H. H., Guo, W., Wang, D., Pan, Y., Sun, J. and Ni, B.-J., 2016. Evaluation of Nitrous Oxide Emission from Sulfide-and Sulfur-Based Autotrophic Denitrification Processes. Environ. Sci. Technol. 50(17), 94079415.

Liu, Y., Ngo, H. H., Guo, W., Zhou, J., Peng, L., Wang, D., Chen, X., Sun, J. and Ni, B.-J., 2017. Optimizing sulfur-driven mixotrophic denitrification process: System performance and nitrous oxide emission. Chem. Eng. Sci. 172, 414-422.

Ludwig, B., Bergstermann, A., Priesack, E. and Flessa, H., 2011. Modelling of crop yields and $\mathrm{N} 2 \mathrm{O}$ emissions from silty arable soils with differing tillage in two long-term experiments. Soil Tillage Res. 112(2), 114-121.

Martin, K.J., Picioreanu, C. and Nerenberg, R., 2013. Multidimensional modeling of biofilm development and fluid dynamics in a hydrogen-based, membrane biofilm reactor (MBfR). Water Res. 47(13), 4739-4751.

Nerenberg, R., 2016. The membrane-biofilm reactor (MBfR) as a counter-diffusional biofilm process. Curr. Opin. Biotechnol. 38, 131-136.

Nerenberg, R., Kawagoshi, Y. and Rittmann, B.E., 2008. Microbial ecology of a perchlorate-reducing, hydrogen-based membrane biofilm reactor. Water Res. 42(4), 1151-1159.

Ni, B.-J., Peng, L., Law, Y., Guo, J. and Yuan, Z., 2014. Modeling of nitrous oxide production by autotrophic ammonia-oxidizing bacteria with multiple production pathways. Environ. Sci. Technol. 48(7), 3916-3924.

Ni, B.-J., Ruscalleda, M., Pellicer-Nacher, C. and Smets, B.F., 2011. Modeling nitrous oxide production during biological nitrogen removal via nitrification and denitrification: extensions to the general ASM models. Environ. Sci. Technol. 45(18), 7768-7776.

Ni, B.-J., Ye, L., Law, Y., Byers, C. and Yuan, Z., 2013. Mathematical modeling of nitrous oxide (N2O) emissions from full-scale wastewater treatment plants. Environ. Sci. Technol. 47(14), 7795-7803.

Pan, Y., Ni, B.-J., Bond, P.L., Ye, L. and Yuan, Z., 2013a. Electron competition among nitrogen oxides reduction during methanol-utilizing denitrification in wastewater treatment. Water Res. 47(10), 3273-3281.

Pan, Y., Ni, B.-J., Lu, H., Chandran, K., Richardson, D. and Yuan, Z., 2015. Evaluating two concepts for the modelling of intermediates accumulation during biological denitrification in wastewater treatment. Water Res. 71, 21-31.

Pan, Y., Ni, B.-J. and Yuan, Z., 2013b. Modeling electron competition among nitrogen oxides reduction and N2O accumulation in denitrification. Environ. Sci. Technol. 47(19), 11083-11091.

Peng, L., Liu, Y., Gao, S.-H., Chen, X. and Ni, B.-J., 2016. Evaluating simultaneous chromate and nitrate reduction during microbial denitrification processes. Water Res. 89, 1-8.

Ravishankara, A.R., Daniel, J.S. and Portmann, R.W., 2009. Nitrous oxide (N2O): the dominant ozone-depleting substance emitted in the 21st century. Science. 326(5949), 123-125.

This article is protected by copyright. All rights reserved 
Reichert, P., 1998. Aquasim 2.0-user manual, computer program for the identification and simulation of aquatic systems. Swiss Federal Institute for Environmental Science and Technology (EAWAG).

Rezania, B., Cicek, N. and Oleszkiewicz, J., 2005. Kinetics of hydrogen- dependent denitrification under varying $\mathrm{pH}$ and temperature conditions. Biotechnol. Bioeng. 92(7), 900-906.

Richardson, D., Felgate, H., Watmough, N., Thomson, A. and Baggs, E., 2009. Mitigating release of the potent greenhouse gas $\mathrm{N} 2 \mathrm{O}$ from the nitrogen cyclecould enzymic regulation hold the key? Trends Biotechnol. 27(7), 388-397.

Rivett, M.O., Buss, S.R., Morgan, P., Smith, J.W. and Bemment, C.D., 2008. Nitrate attenuation in groundwater: a review of biogeochemical controlling processes. Water Res. 42(16), 4215-4232.

Sabba, F., Picioreanu, C., Pérez, J. and Nerenberg, R., 2015. Hydroxylamine Diffusion Can Enhance N2O Emissions in Nitrifying Biofilms: A Modeling Study. Environ. Sci. Technol. 49(3), 1486-1494.

Sabba, F., Picioreanu, C. and Nerenberg, R., 2017. Mechanisms of Nitrous Oxide (N2O) Formation and Reduction in Denitrifying Biofilms. Biotechnol. Bioeng. 114, 2753-2761.

Sahu, A.K., Conneely, T., Nüsslein, K. and Ergas, S.J., 2009. Hydrogenotrophic denitrification and perchlorate reduction in ion exchange brines using membrane biofilm reactors. Biotechnol. Bioeng. 104(3), 483-491.

Smith, R.L., Buckwalter, S.P., Repert, D.A. and Miller, D.N., 2005. Small-scale, hydrogen-oxidizing-denitrifying bioreactor for treatment of nitrate-contaminated drinking water. Water Res. 39(10), 2014-2023.

Tang, Y., Zhao, H., Marcus, A.K., Krajmalnik-Brown, R. and Rittmann, B., E, 2012a. A steady-state biofilm model for simultaneous reduction of nitrate and perchlorate, part 1: model development and numerical solution. Environ. Sci. Technol. 46(3), 1598-1607.

Tang, Y., Zhao, H., Marcus, A.K., Krajmalnik-Brown, R. and Rittmann, B., E, 2012b. A steady-state biofilm model for simultaneous reduction of nitrate and perchlorate, part 2: parameter optimization and results and discussion. Environ. Sci. Technol. 46(3), 1608-1615.

Tang, Y., Zhou, C., Ziv-El, M. and Rittmann, B.E., 2011. A pH-control model for heterotrophic and hydrogen-based autotrophic denitrification. Water Res. 45(1), 232-240.

Vasiliadou, I., Siozios, S., Papadas, I., Bourtzis, K., Pavlou, S. and Vayenas, D., 2006. Kinetics of pure cultures of hydrogen- oxidizing denitrifying bacteria and modeling of the interactions among them in mixed cultures. Biotechnol. Bioeng. 95(3), 513-525.

Wang, D., Liu, Y., Ngo, H. H., Zhang, C., Yang, Q., Peng, L., He, D., Zeng, G., Li, X. and Ni, B.-J., 2017a. Approach of describing dynamic production of volatile fatty acids from sludge alkaline fermentation. Bioresour. Technol. 238, 343-351.

Wang, D., Wang, Y., Liu, Y., Ngo, H. H., Lian, Y., Zhao, J., Chen, F., Yang, Q., Zeng, G. and Li, X., 2017b. Is denitrifying anaerobic methane oxidation-centered

This article is protected by copyright. All rights reserved 
technologies a solution for the sustainable operation of wastewater treatment Plants?. Bioresour. Technol. 234, 456-465.

Zhang, J., Cai, Z. and Zhu, T., 2011. N2O production pathways in the subtropical acid forest soils in China. Environ. Res. 111 (5), 643-649.

Zhao, H.-P., Ilhan, Z.E., Ontiveros-Valencia, A., Tang, Y., Rittmann, B.E. and Krajmalnik-Brown, R., 2013a. Effects of multiple electron acceptors on microbial interactions in a hydrogen-based biofilm. Environ. Sci. Technol. 47(13), 7396-7403.

Zhao, H.-P., Ontiveros-Valencia, A., Tang, Y., Kim, B.O., Ilhan, Z.E., KrajmalnikBrown, R. and Rittmann, B., 2013b. Using a two-stage hydrogen-based membrane biofilm reactor (MBfR) to achieve complete perchlorate reduction in the presence of nitrate and sulfate. Environ. Sci. Technol. 47(3), 1565-1572.

Zhao, H.-P., Van Ginkel, S., Tang, Y., Kang, D.-W., Rittmann, B. and KrajmalnikBrown, R., 2011. Interactions between perchlorate and nitrate reductions in the biofilm of a hydrogen-based membrane biofilm reactor. Environ. Sci. Technol. 45(23), 10155-10162. 


\section{Table Captions}

Table 1. Stoichiometric Matrix and Process Kinetic Rate Equations for the Developed Model

\section{Figure Captions}

Figure 1. Fits between the experimental and model simulated $\mathrm{NO}_{3}{ }^{-}, \mathrm{NO}_{2}{ }^{-}$, and $\mathrm{N}_{2} \mathrm{O}$ profiles at $30{ }^{\circ} \mathrm{C}$ achieved in model calibration: (a) $\mathrm{NO}_{3}{ }^{-}$as the initial electron acceptor, with an IC/ $\mathrm{N}$ ratio of 1.8 and a constant dissolved hydrogen concentration of $0.40 \mathrm{mg} / \mathrm{L}$; (b) $\mathrm{N}_{2} \mathrm{O}$ as the initial electron acceptor, with an IC/N ratio of 1.8 and a constant dissolved hydrogen concentration of $0.40 \mathrm{mg} / \mathrm{L}$; (c) $\mathrm{NO}_{3}{ }^{-}$as the initial electron acceptor, with an IC/ $\mathrm{N}$ ratio of 0.18 and a constant dissolved hydrogen concentration of $0.40 \mathrm{mg} / \mathrm{L}$; (d) $\mathrm{NO}_{3}{ }^{-}$as the initial electron acceptor, with an IC/N ratio of 0 and a constant dissolved hydrogen concentration of $0.40 \mathrm{mg} / \mathrm{L}$; (e) $\mathrm{NO}_{3}{ }^{-}$as the initial electron acceptor, with an IC/ $\mathrm{N}$ ratio of 1.8 and a constant dissolved hydrogen concentration of $0.17 \mathrm{mg} / \mathrm{L}$; and (f) $\mathrm{NO}_{3}{ }^{-}$as the initial electron acceptor, with an IC/ $\mathrm{N}$ ratio of 1.8 and a constant dissolved hydrogen concentration of 0.02 $\mathrm{mg} / \mathrm{L}$.

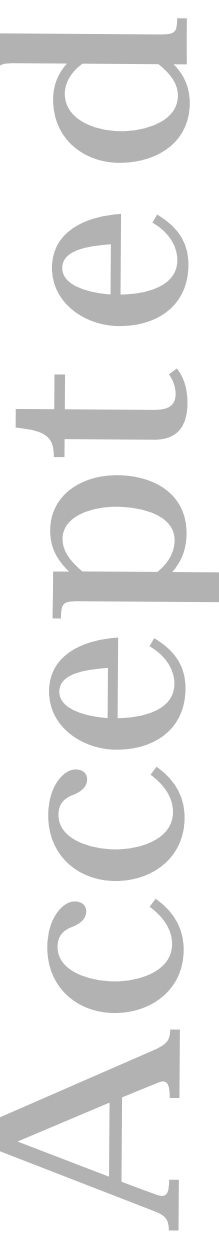

Figure 2. Fits between experimental and simulated $\mathrm{NO}_{3}{ }^{-}, \mathrm{NO}_{2}{ }^{-}$, and $\mathrm{N}_{2} \mathrm{O}$ profiles achieved in model validation with $\mathrm{NO}_{3}{ }^{-}$as the initial electron acceptor under an IC/N ratio of 1.8 and a constant dissolved hydrogen concentration of $0.40 \mathrm{mg} / \mathrm{L}$ : (a) $20^{\circ} \mathrm{C}$; (b) $25^{\circ} \mathrm{C}$; and (c) $35^{\circ} \mathrm{C}$.

Figure 3. Fits between experimental and simulated $\mathrm{NO}_{3}{ }^{-}$and $\mathrm{NO}_{2}{ }^{-}$profiles achieved in model evaluation under a $\mathrm{NaHCO}_{3}$ concentration of $2.5 \mathrm{~g} / \mathrm{L}$ with different initial nitrate concentrations: (a) 20; (b) 30; and (c) $50 \mathrm{mg}-\mathrm{N} / \mathrm{L}$.

Figure 4. Fits between experimental and simulated $\mathrm{NO}_{3}{ }^{-}$and $\mathrm{NO}_{2}{ }^{-}$profiles achieved in model evaluation under an initial nitrate concentration of $20 \mathrm{mg}-\mathrm{N} / \mathrm{L}$ with different initial $\mathrm{NaHCO}_{3}$ concentrations: (a) 0; (b) 20; (c) 200; and (d) 1250 mg- $\mathrm{NaHCO}_{3} / \mathrm{L}$.

Figure 5. (a) Experimental and simulated reduction rates of $\mathrm{NO}_{3}{ }^{-}, \mathrm{NO}_{2}{ }^{-}$or $\mathrm{N}_{2} \mathrm{O}$ with 7 nitrogen oxides addition schemes that include: (1) $\mathrm{NO}_{3}{ }^{-}$, (2) $\mathrm{NO}_{2}{ }^{-}$, (3) $\mathrm{N}_{2} \mathrm{O}$, (4) $\mathrm{NO}_{3}{ }^{-}$and $\mathrm{NO}_{2}{ }^{-}$, (5) $\mathrm{NO}_{3}{ }^{-}$and $\mathrm{N}_{2} \mathrm{O},(6) \mathrm{NO}_{2}{ }^{-}$and $\mathrm{N}_{2} \mathrm{O}$, (7) $\mathrm{NO}_{3}{ }^{-}, \mathrm{NO}_{2}{ }^{-}$, and $\mathrm{N}_{2} \mathrm{O}$; and (b) Electron consumption rates by Nar, Nir, Nor, and Nos under non-hydrogen-andIC-limiting conditions.

Figure 6. Simulated electron distribution with two or three nitrogen oxides added in each test. Hydrogen addition schemes C, H1, H2, H3, H4, and H5 stand for hydrogen pulse feeding (12 mmol/L) and hydrogen slow feeding with loading rates of 12,6 , 2.4, 1.2, $0.6 \mathrm{mmol} /(\mathrm{L} \times \mathrm{h})$ ), respectively: (a) $\mathrm{NO}_{3}{ }^{-}$and $\mathrm{NO}_{2}{ }^{-}$were added; (b) $\mathrm{NO}_{3}{ }^{-}$ and $\mathrm{N}_{2} \mathrm{O}$ were added; (c) $\mathrm{NO}_{2}{ }^{-}$and $\mathrm{N}_{2} \mathrm{O}$ were added; and (d) $\mathrm{NO}_{3}{ }^{-}, \mathrm{NO}_{2}{ }^{-}$, and $\mathrm{N}_{2} \mathrm{O}$ were added. 
Table 1. Stoichiometric Matrix and Process Kinetic Rate Equations for the Developed Model

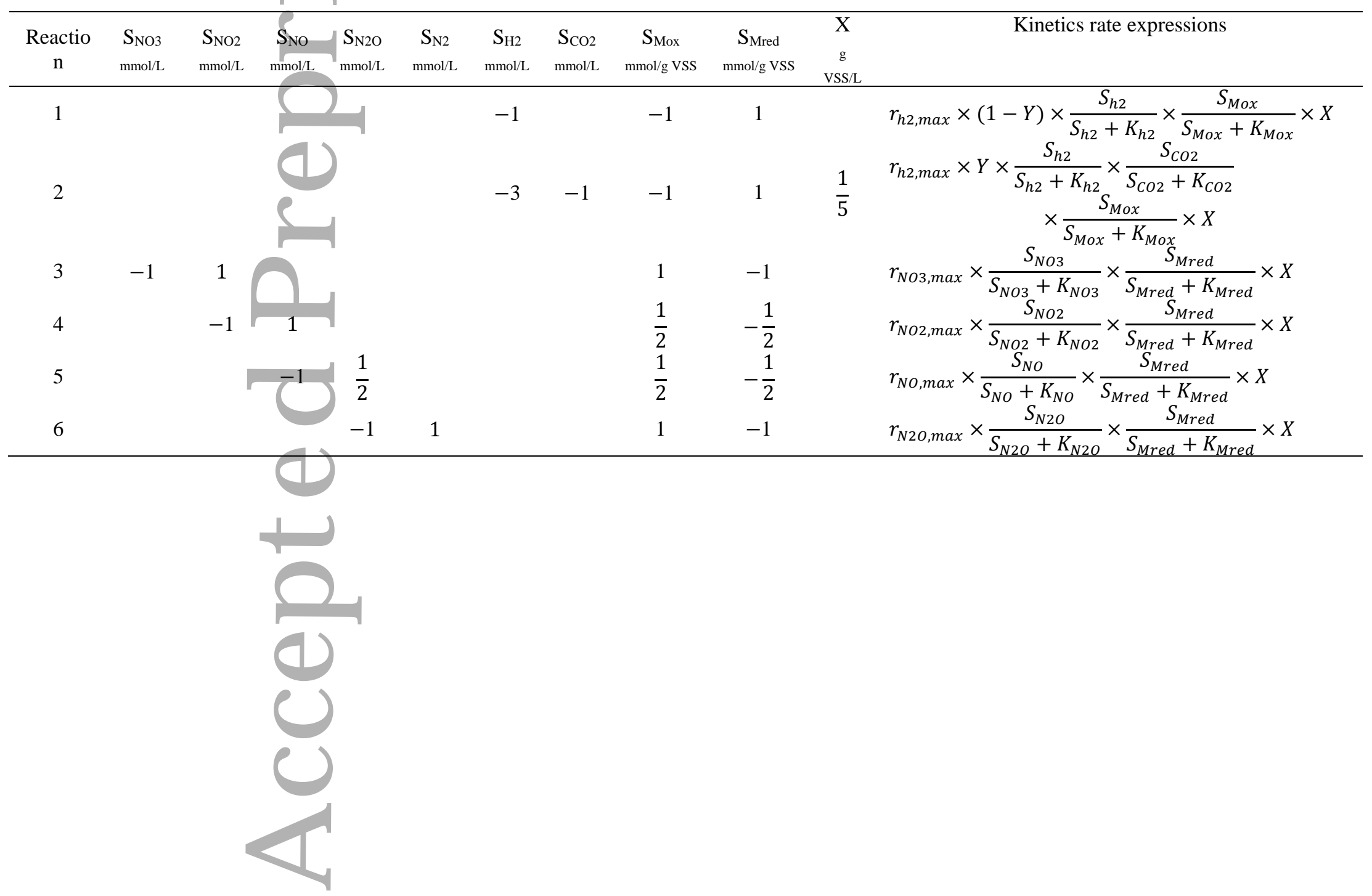

This article is protected by copyright. All rights reserved 

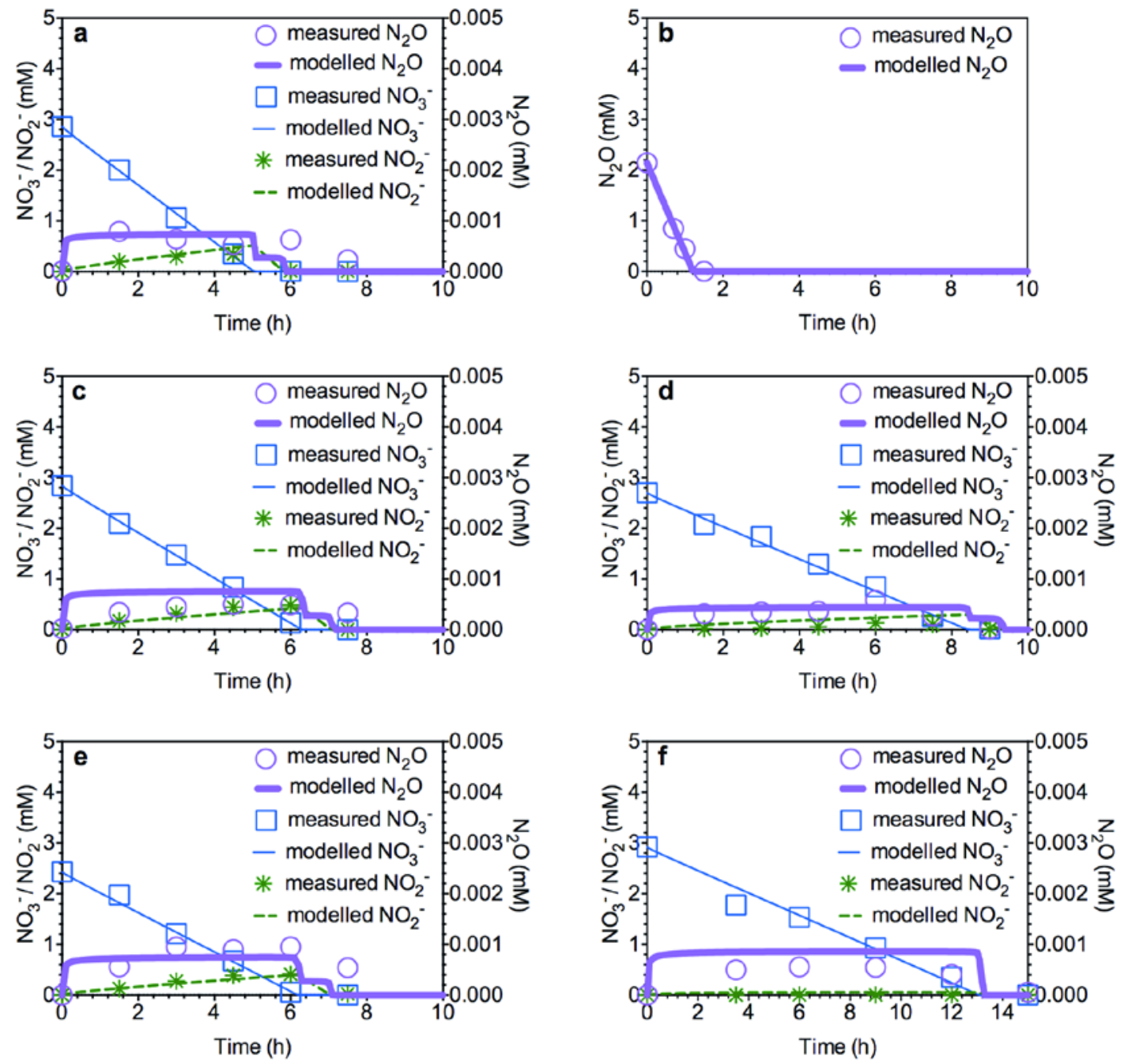

Figure 1 

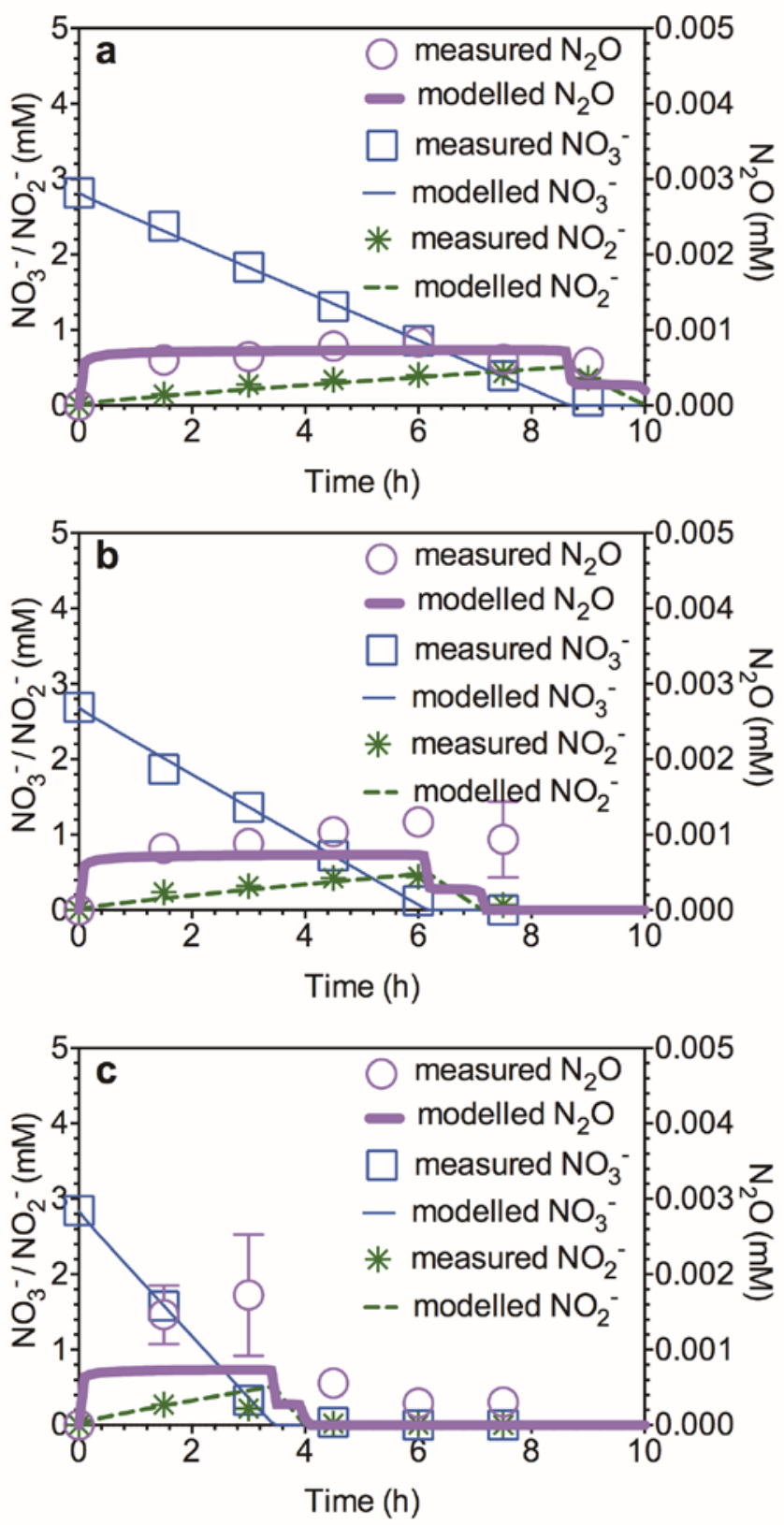

Figure 2 

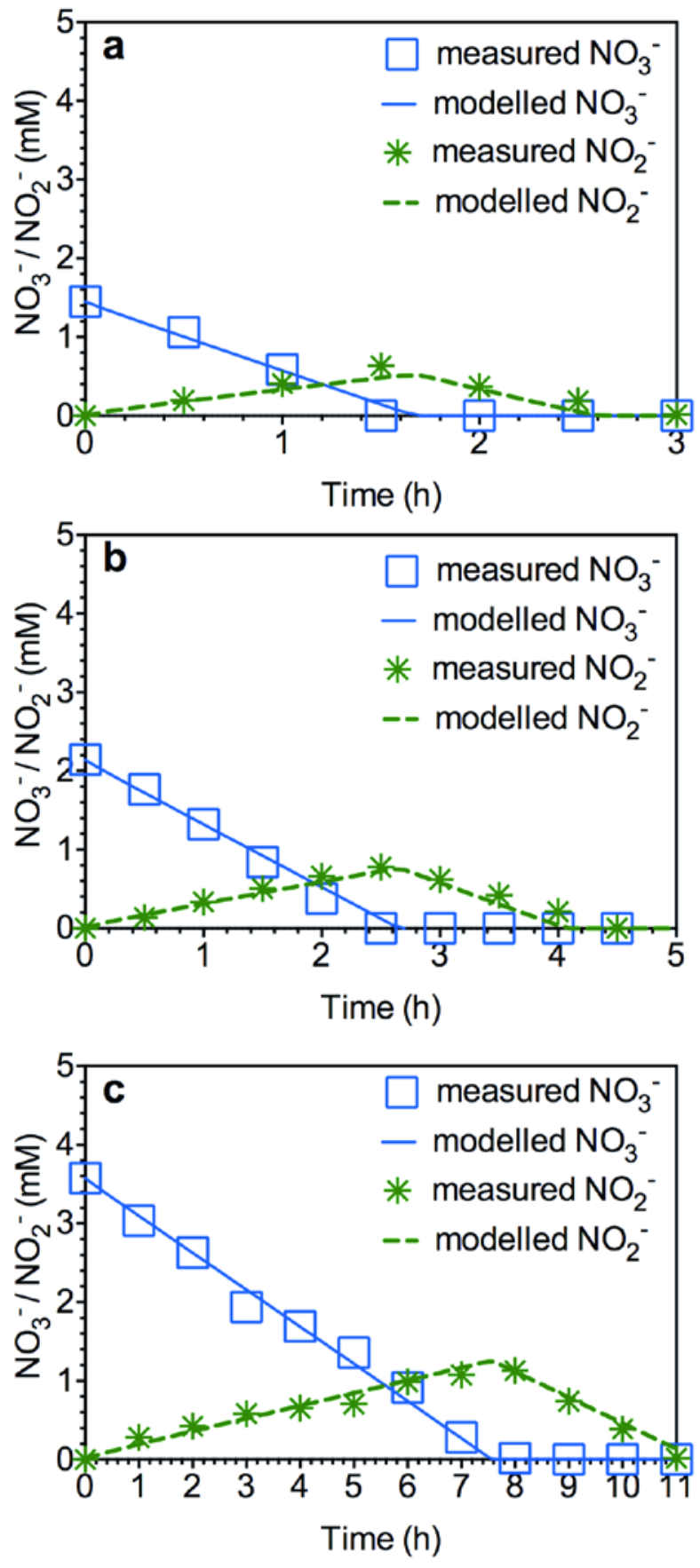

Figure 3 

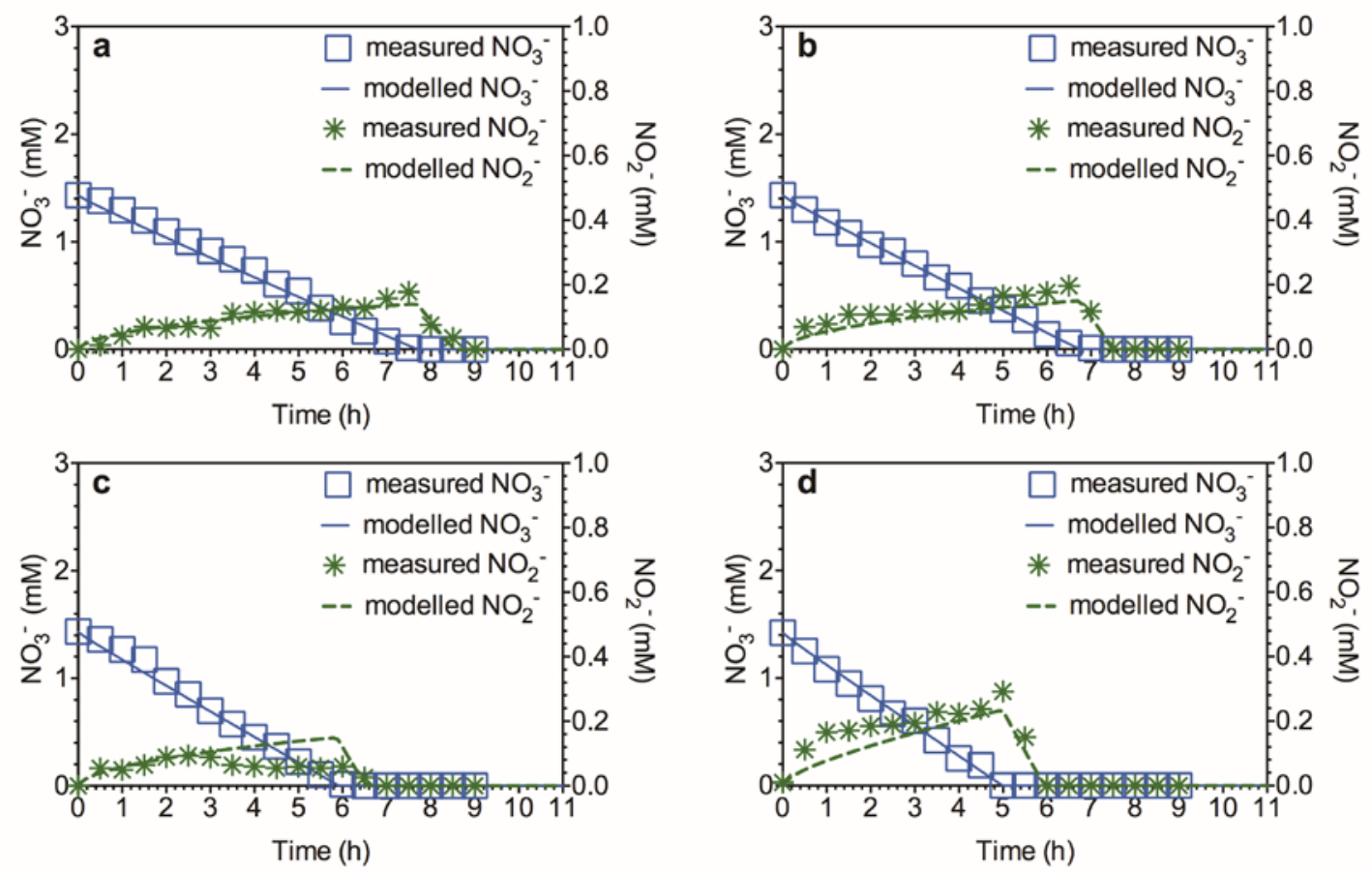

Figure 4

This article is protected by copyright. All rights reserved 


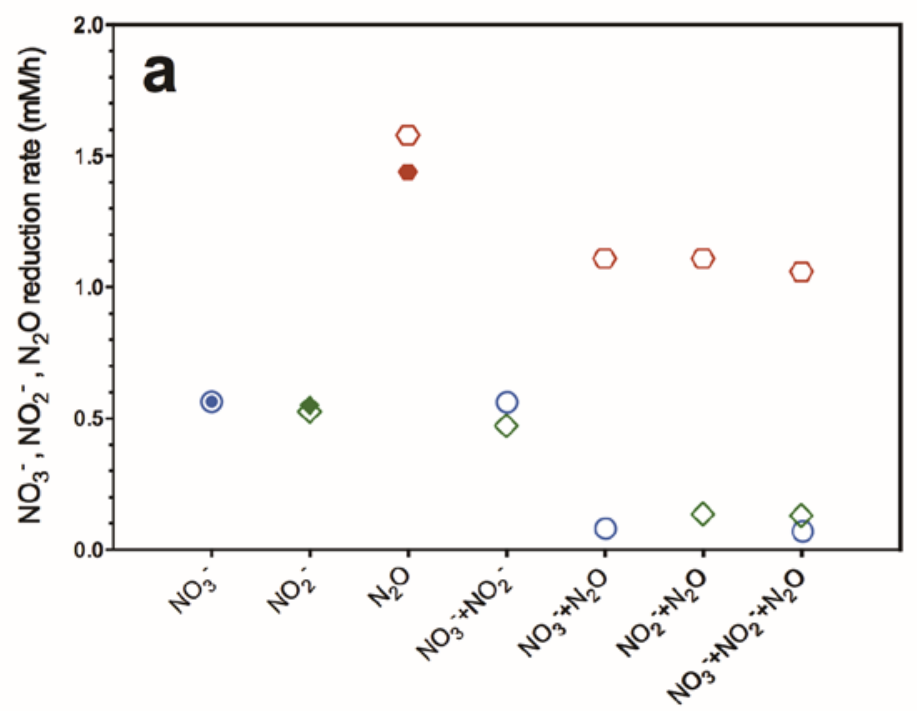

O $\mathrm{NO}_{3}{ }^{-}$modelled

- $\mathrm{NO}_{3}^{-}$measured

$\diamond \mathrm{NO}_{2}^{-}$modelled

- $\mathrm{NO}_{2}^{-}$measured

$\checkmark \mathrm{N}_{2} \mathrm{O}$ modeled

- $\mathrm{N}_{2} \mathrm{O}$ measured

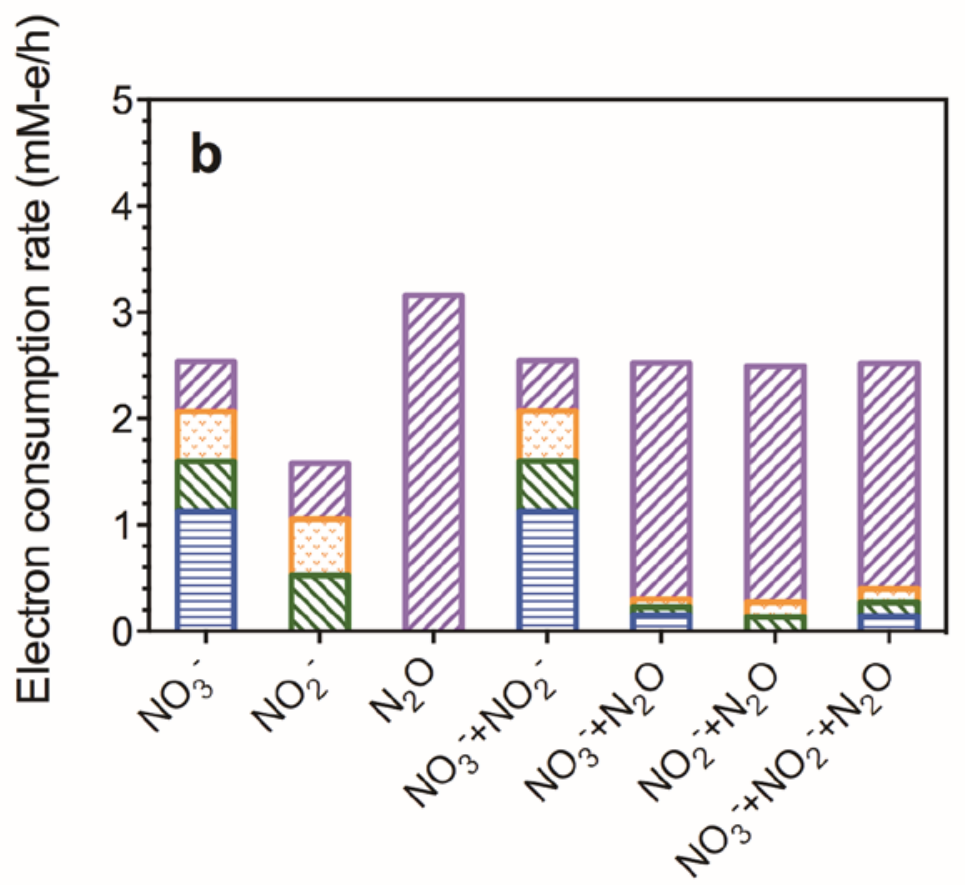

冒 $\mathrm{NO}_{3}{ }^{-}$modelled

$\mathbb{N} \mathrm{NO}_{2}^{-}$modelled

圆 NO modelled

$\square \mathrm{N}_{2} \mathrm{O}$ modelled

Figure 5 

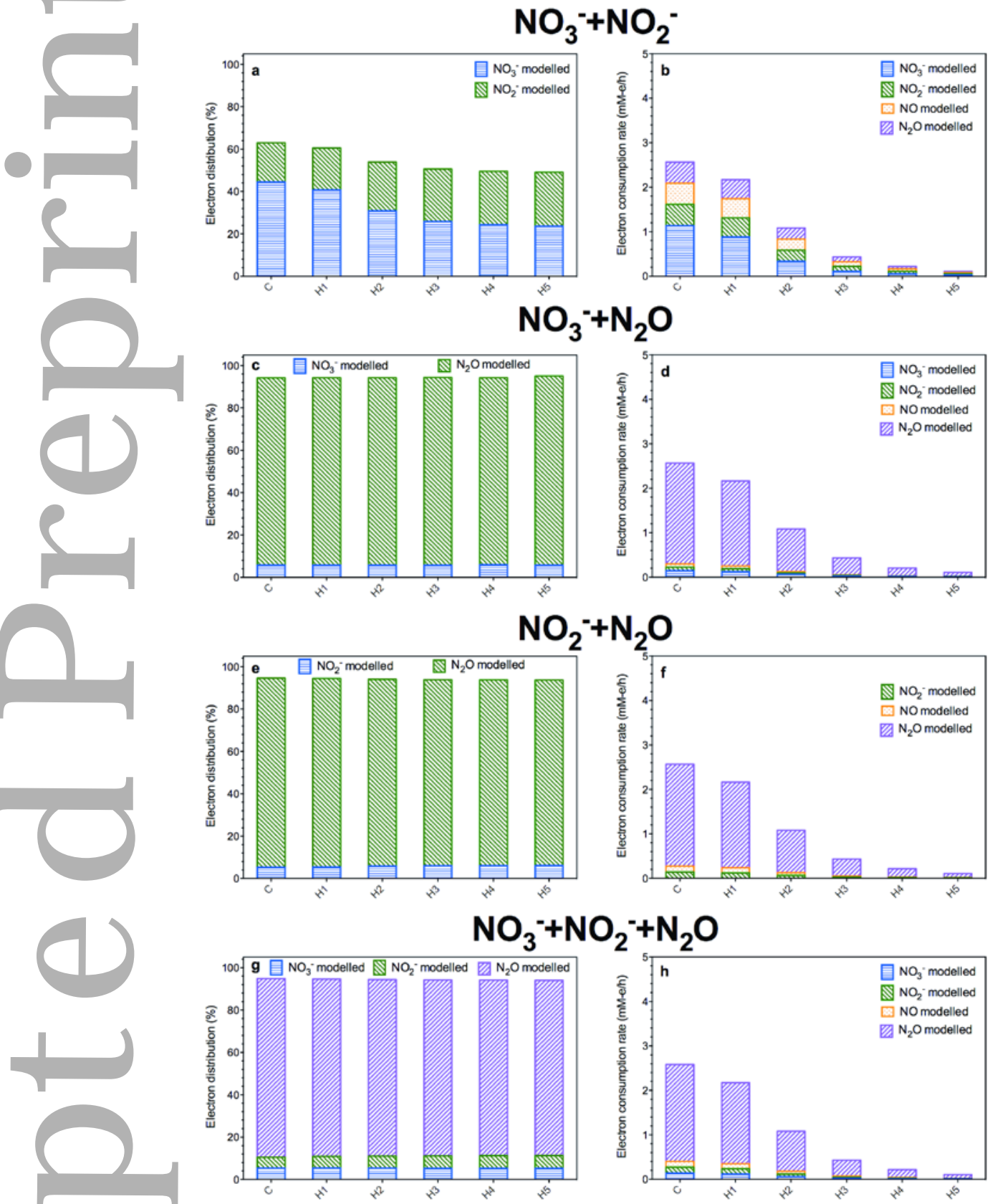

Figure 6 